\title{
PUNTOS DE INTERSECCIÓN ENTRE LOS ISMOS CONSTITUCIONALES'
}

Óscar Alexis Agudelo Giraldo

Universidad Católica de Colombia

\section{INTERSECTIONS BETWEEN CONSTITUTIONAL ISMS}

DOI: $1017450 / 160111$

\section{Introducción: Los puntos del debate entre constitucionalismo y neoconstitucionalismo}

El advenimiento del paradigma constitucionalista y su demarcación espacial en el nacimiento de los Estados constitucionales de derecho deben su desarrollo a sistemas jurídicos que proceden de tradiciones distintas -Common law y derecho continental europeo-, pero que pueden guardar serias relaciones de continuidad en el modelo de solución a la dimensión trilemática de la filosofía del derecho -validez, eficacia y legitimidad- y reducir el trilema a la interpenetración del sistema teórico de la legitimidad en sede de filosofía del derecho a los sistemas, también teóricos; de la validez, en sede de teoría jurídica, y eficacia, en sede de sociología del derecho. Para ello, se erigen las teorías de la democracia constitucional y el constitucionalismo democrático, de amplio

1. El presente artículo se estructura como desarrollo del proyecto de investigación "Metodología del positivismo jurídico. Metateoría y constitucionalismo moderno" del Grupo de estudios legales y sociales Phronesis, adscrito al Centro de Investigaciones Socio Jurídicas (CISJUC) de la Facultad de Derecho de la Universidad Católica de Colombia. 
uso en la tradición de ambos tipos de sistema jurídico. ${ }^{2}$ Las diferencias vendrán a ser de unidades temáticas y categorías de análisis, las cuales, sin embargo, no llegan a alterar de manera radical una misma hipótesis final. De aquí que, mientras en la tradición norteamericana el constitucionalismo democrático es una tipología de los ismos constitucionales, que a su vez subyacen a las formas incluyente y excluyente de positivismos, en el sistema de derecho continental europeo aparece la figura del neoconstitucionalismo como un paradigma postpositivista, en superación de la noción ideológica, metodológica y teórica del positivismo jurídico. Como punto de partida, el neoconstitucionalismo representa una teoría sostenida durante los últimos cincuenta años, con referencia específica al desarrollo teórico y operativo del Estado constitucional de derecho. A pesar de erigirse como una tesis que supera los postulados del positivismo jurídico, recoge metodológicamente las relaciones de tipo necesario, contingente e hipotético entre el derecho y la moral.

Frente a la constitucionalización del derecho, en el ámbito del derecho continental europeo, Comanducci encuentra dos transformaciones operativas:

i) La constitucionalización del derecho como transformación de tipo estructural;

ii) El neoconstitucionalismo como transformación doctrinal. ${ }^{3}$

Siendo así, constitucionalizar el derecho implica, en términos de Comanducci, permear o invadir, de manera condicionante, la legislación, jurisprudencia y doctrina, actividad que se viene desarrollando con la actividad jurisdiccional de los tribunales constitucionales. Lo anterior sostiene la hipótesis de la noción sistemática del derecho como una reconstrucción interna de este, donde en la técnica del precedente judicial, se reestructuran los axiomas jurídicos del sistema legal. ${ }^{4}$ Para ello, la tesis de reconstrucción interna devendrá de las teorías de la legitimidad democrática en conexión con el paradigma del constitucionalismo democrático.

Por otra parte, en la versión de la escuela genovesa -sobre la cual sus representantes se abrogan la creación de la expresión neoconstitucionalismo- se presenta una superación de los paradigmas del positivismo jurídico y el iusnaturalismo. Por otro lado, pareciendo una tesis ecléctica de las teorías americanas y continentales, Aguiló encuentra

\footnotetext{
2. Véase: L. Ferrajoli, Principia Iuris. Teoría del derecho y de la democracia. I. Teoría del Derecho, Trotta, Madrid, 2011, p. 11. 3. Véase: P. Comanducci, “Constitucionalización y neoconstitucionalismo", en P. Comanducci, A. Ángeles, D. González (eds.), Positivismo jurídico y neoconstitucionalismo, Fundación Coloquio Jurídico Europeo, Madrid, 2009, p. 85.

4. En conexión con el paradigma norteamericano, sobresale la figura del constitucionalismo del árbol vivo, el cual parte de la función judicial, en cuya actividad es posible, a través del precedente, expandir las democracias actuales. Véase: J. Fabra, "Wilfrid Waluchow. Positivismo jurídico incluyente y constitucionalismo del árbol vivo", en Academia.edu, https:// www.academia.edu/14864203/Wilfrid_J._Waluchow_Positivismo_jur\%C3\%ADdico_incluyente_y_constitucionalismo_ del_arbol_vivo_.
} 
en el modelo constitucionalista una fase postpositivista del derecho, en superación del paradigma positivista legalista.

\section{Constitucionalización y constitucionalismo}

Podrían delimitarse, acudiendo a un argumento de autoridad en Guastini, las características definitorias del fenómeno de constitucionalización del derecho. Sin embargo, debe advertirse que estas representarán al fenómeno como un desarrollo gradual, siendo entre otras sus características definitorias:

i) Un margen de rigidez constitucional. El cual puede equipararse, en la correlación de sistemas jurídicos, a la posición originalista norteamericana; ${ }^{5}$

ii) La garantía jurisdiccional de la constitución de la mano de la rigidez constitucional;

iii) La fuerza vinculante de la constitución, donde desaparecen las normas programáticas como simples recomendaciones políticas ya que no pueden ser incumplidas. Sin embargo, no existe una teoría fuerte que distinga la categoría normativa en ámbito de aplicabilidad de los valores constitucionales, los principios y las directrices programáticas; ${ }^{6}$

iv) Se traslada de la interpretación literal a la interpretación extensiva de la constitución, lo cual supedita la extracción de principios implícitos en normas constitucionales; lo que equivale en el modelo estadounidense a la creación de principios innominados; ${ }^{7}$

v) La naturaleza de aplicación directa de las normas constitucionales;

vi) La imposición del canon de interpretación conforme a la constitución;

vii) La influencia de la constitución sobre los debates y procesos políticos. ${ }^{8}$

\footnotetext{
5. En el ámbito del constitucionalismo estadounidense, las tesis originalistas presentan dos puntos de vista: i) una fidelidad constitucional apegada al texto constitucional, ii) una fidelidad constitucional que se asienta en las prácticas constitucionales del pasado. Véase: R. Dworkin, “The Ardous Virtue of Fidelity: Originalism, Scalia, Tribe, and Nerve”, en Fordham Law Review, 65, 1997, p. 149.

6. Un nuevo enfoque para esta distinción obra en H. Ávila, Teoría de los principios, Marcial Pons, Madrid, 2011, p. 165.

7. Las prácticas de los Tribunales Constitucionales han demostrado, al menos para Latinoamérica, la inferencia de principios jurídicos subyacentes o principios innominados, cuya existencia deviene de enunciados jurídicos o proposiciones normativas, dadas en la función judicial. Véase: A. Bunter. "Consideraciones en torno a la dogmática penal", en Boletín mexicano de derecho comparado, 30, 1997, pp. 935 y ss.; R. Dworkin, "Unenumerated Rights: Wheter and How Roe Should Be Overruled”, en University of Chicago Law Review, 59, 1992, pp. 381 y ss.; C. Courtis, "El juego de los juristas. Ensayo de caracterización de la investigación dogmática”, en C. Courtis (ed.), Observar la ley. Ensayos sobre metodología de la investigación jurídica. Trotta, Madrid, 2006, pp. 105 y ss.

8. Véase: J. Aguiló, “Positivismo y postpositivismo. Dos paradigmas jurídicos en pocas palabras”, en Doxa, 30, 2007 , p. 667.
} 
La recepción del cambio de paradigma soporta en la actualidad dos posiciones. Primero, quienes proponen la creación de un nuevo paradigma jurídico para un nuevo fenómeno jurídico. Segundo, quienes no encuentran la necesidad de crear un nuevo paradigma jurídico para un nuevo fenómeno jurídico. Para ello, estima Aguiló, los cambios que trae el paradigma constitucionalista son de tipo gradual: si los cambios son de tipo cuantitativo, no resultará necesario crear un nuevo paradigma teórico pero, si son de tipo cualitativo, requerirá reformular las teorías que soportan el paradigma. Bajo el juicio de Aguiló, a los primeros, que no encuentran necesidad de reformulación teórica, se les suele denominar positivistas y a los segundos, partidarios de una nueva visión teórica, se les denominará postpositivistas o neoconstitucionalistas. ${ }^{9} \mathrm{Al}$ respecto, sobresale una incógnita auxiliar para desarrollar que implica la posibilidad de ubicar o no las teorías del positivismo jurídico incluyente en un marco constitucionalista.

Para Prieto Sanchís, el constitucionalismo presenta una versión de la teoría del derecho adversa a la teoría del derecho positivo. Siendo así, el nuevo horizonte de esta viene dado, a juicio de Sanchís, en la materialización de la constitución a través del sistema de garantías; posición a la cual denomina “constitucionalismo de los derechos".

El contenido material de la constitución implica una serie de elementos normativos que se presentan en distintas denominaciones y categorías normativas: "Valores, principios, derechos o directrices." ${ }^{10}$ Desde luego, la protección del contenido material de la constitución es un rol que corresponde a los tribunales constitucionales. Sin embargo, la tesis de la garantía jurisdiccional de la constitución sobresale como un límite a la concepción procedimental de la democracia, determinando no con exclusividad sobre lo que se puede decidir, sino además sobre aquello que no se debe dejar de decidir. No sobra advertir que: "Aquello que temía Kelsen representa hoy la señal de identidad del nuevo constitucionalismo; este no solo gira en torno a los derechos o, si se quiere también, a los valores y principios." 11

Otras de las posiciones subsecuentes al debate entre neoconstitucionalismo y positivismo jurídico devienen de la afirmación según la cual con el constitucionalismo se ha positivizado el derecho natural. Considerar plausible la posición anterior implicaría que el estatuto epistemológico de la teoría del derecho se ha reconfigurado a partir del nuevo paradigma. De ahí que una de las preguntas persistentes sea la de cuál ha de ser la teoría y filosofía del derecho para desarrollar a partir de la constitucionalización. Lo

9. Ibid., p. 668 .

10. L. Prieto Sanchís, "El constitucionalismo de los derechos”, en M. Carbonell (ed.), Teoría del constitucionalismo. Ensayos recogidos, Trotta, Madrid, 2009, p. 213.

11. Ibid., p. 215. 
anterior cobra mayor evidencia, pues "En suma, el positivismo jurídico se configura como una teoría general y descriptiva del derecho. Entiende que la función de la teoría del derecho es dar cuenta de la realidad jurídica, es decir, suministrar herramientas y conceptos para comprender mejor el funcionamiento del derecho." ${ }^{12}$

Escudero Alday recuerda que dos han sido las estrategias para superar el modelo de teoría del derecho del positivismo jurídico:

i) Circunscribir al positivismo jurídico al legecentrismo; situación que no se acomoda con la supremacía constitucional;

ii) La lectura moral de la constitución, dada la incorporación de principios y valores.

En las posiciones (i) y (ii) de Escudero persiste, sin embargo, un examen al paelopositivismo jurídico. No se toma como objeto de consideración la relación entre positivismo jurídico incluyente y neoconstitucionalismo; situación que marcaría parte del estado del arte en el debate.

La réplica constitucionalista a las tesis del neoconstitucionalismo deriva de la inexistencia de una nueva teoría propiamente dicha, de ahí que puede equivaler a nada más que "la acumulación de tesis normativas." ${ }^{33}$ En continuidad con la incógnita sobre el estatuto del neoconstitucionalismo, Barberis señala tres problemas de utilidad: i) ¿Cómo conviene definir y reconstruir el neoconstitucionalismo?, ii) ¿El neoconstitucionalismo representa una alternativa teórica plausible al positivismo?, iii) ¿Escapa alguna teoría del derecho al componente ideológico? De ahí que se constituyan algunos de los tópicos de la perspectiva neoconstitucionalista:

i) La distinción derecho y moral;

ii) La distinción entre reglas y principios;

iii) Los mecanismos de aplicación de reglas y principios por subsunción y ponderación. ${ }^{14}$

Ubicándose en el debate derecho y moral, la tesis constitucionalista ubica la relación del papel de los principios constitucionales en la dinámica del Estado constitucional; así se sitúa como punto intermedio entre las posiciones iusnaturalistas y positivistas. "En el

12. R. Escudero, "De la constitucionalización a la indeterminación: retos y desafíos del positivismo jurídico", en Anales de la Cátedra Francisco Suárez, 44, 2010, p. 398.

13. M. Barberis, “¿Existe el neoconstitucionalismo?”, en J. Fabra (ed.), Filosofía del derecho constitucional. Cuestiones fundamentales, Universidad Nacional Autónoma de México, México D.F., 2015, p. 455.

14. Ibid., p. 463. 
Estado constitucional, caracterizado por la rigidez de la constitución y el control constitucional de las leyes, la situación cambia; aquí los valores morales, externos al derecho positivo, se convertirán en principios constitucionales, internos a este."15

En segunda medida, tratándose de la distinción entre reglas y principios, el punto de partida del modelo neoconstitucionalista sobrevendrá en la posición de Dworkin en los derechos en serio y en Alexy, donde obra una distinción fuerte entre principio y regla como normas que se caracterizan mutuamente por ser exhaustivas. Por otra parte, una distinción débil de ambas categorías normativas implica que "la regla indica normas que guían directamente la conducta [...] El principio, normas que guían la conducta indirectamente por medio de reglas"; ${ }^{16}$ posición que implicaría la tesis de la concreción de los principios a través de las reglas. ${ }^{17}$

En tercera medida, tratándose de la aplicación de reglas y principios, Barberis presenta las cinco tesis del neoconstitucionalismo:

i) "El conflicto de principios ocultaría un orden objetivo de valores"; ${ }^{18}$

ii) La ponderación se emplea frente a casos constitucionales difíciles; ${ }^{19}$

iii) En casos extremos se puede sacrificar un principio por otro;

iv) La ponderación solo es operativa en el caso concreto; ${ }^{20}$

v) Ponderación y subsunción se excluyen mutuamente. Sin embargo, "la aplicación de un principio genérico implica la especificación de este en una regla." ${ }^{21}$

En defensa de la tesis positivista, acorde con el contenido material simultáneo del cual están provistas las constituciones, la aparición de categorías normativas no comunes al arquetipo de reglas y normas jurídicas, para García Amado, constituyen un problema que no ha dejado de rondar en los límites del positivismo jurídico, en tanto,

15. Ibid., p. 464.

16. Ibid., p. 466.

17. Véase: K. Engisch, La idea de concreción en el derecho y en la ciencia jurídica actuales, Comares, Madrid, 2004.

18. Sin embargo, bajo una pluralidad de valores el debate implicará retomar la tesis de la unidad de valor o, por otro lado, la tesis de la interpretación puntual de los valores a partir de un punto y momento fijo de observación. Véase: R. Dworkin, Justice for hendgehogs, Harvard University Press, Cambridge (Mass.), 2011; C. Schmitt, La tirana de los valores, Hydra, Buenos Aires, 2012.

19. Las prácticas constitucionales demuestran entre otras tipologías de casos difíciles: i) la colisión de derechos fundamentales o principios, ii) la laguna normativa presente en el evento de una laguna constitucional, iii) la laguna axiológica, conexa con el control de constitucionalidad por excepción, iv) las lagunas de conocimiento. Para los puntos i, ii, iii confróntese: O. Agudelo, "Dos dilemas judiciales en Ronald Dworkin", en Novum Jus: Revista de la Facultad de Derecho de la Universidad Católica de Colombia, 8, 2014, pp. 39-40. Para el punto iv confróntese: C. Alchourron, E. Bulygin, Sistemas normativos: introducción a la metodología de las ciencias jurídicas y sociales, Astrea, Bogotá, 2013, pp. 203 y ss. 20. De ahí que no sea plausible declarar la existencia de precedente judicial, derivado de una ponderación de derechos. 21. M. Barberis, “¿Existe el neoconstitucionalismo?”, p. 468. 
son problemas que no dejan de ser expresados a través del lenguaje normativo. Para ello, frente al contenido material de la constitución procede un análisis deóntico en tres posiciones:

i) Cosas que la constitución claramente dice (estados de cosas, acompañados de operadores deónticos: $\mathrm{Op}, \mathrm{Pp},-\mathrm{Pp}$ );

ii) Cosas de las que la constitución no dice absolutamente nada, por lo que se encuentra en presencia de lagunas constitucionales (Øp);

iii) Cosas de las que no sabemos si la constitución dice algo o no, abogando por las tesis indeterministas sobre el contenido normativo constitucional $(\mathrm{v}(\mathrm{Pp}) \mathrm{v}(\mathrm{P}-\mathrm{p}))^{22}$.

De la relación entre i, ii y iii es posible distinguir que, en materia de categorías y elementos del contenido material constitucional, sobresale una de las tesis útiles para distanciar el constitucionalismo del neoconstitucionalismo, y será el carácter abierto o cerrado del contenido de lo que la constitución dice semánticamente. Sobre ello, una de las incógnitas que merecen ser exploradas es la posibilidad de derivar un mandato constitucional de un enunciado constitucional semánticamente indeterminado. ${ }^{23}$

A la respuesta sobre la diferenciación entre constitucionalismo y neoconstitucionalismo, García Amado referencia serias distinciones, que pueden ser parafraseadas así:

El paradigma constitucionalista se caracteriza por:

i) Una dependencia del contenido deóntico de los mandatos constitucionales a la referencia de sus términos; ii) Frente a los problemas de indeterminación de las normas de orden constitucional, se reconoce que la constitución es abierta y, puede concretarse en contra de la semántica constitucional; iii) En aquellos problemas de indeterminación semántica derivados de la formulación lingüística de las normas constitucionales, la elección de la mejor interpretación solo corresponde a los intérpretes autorizados (legislador, jueces y Tribunal constitucional;

22. Véase: A. García Amado, “Derechos y pretextos. Elementos de crítica del neoconstitucionalismo”, en M. Carbonell (ed.), Teoría del constitucionalismo. Ensayos recogidos, p. 238. 23. Ibid. 
iv) El Tribunal constitucional cumple un rol negativo puro, pues solo desecha del ordenamiento jurídico aquellas normas que pasan por el filtro del control de constitucionalidad; v) Al poder legislativo le es dada la función de realización constitucional; vi) Persiste una defensa de las figuras del legislador democrático y la soberanía popular. ${ }^{24}$

Por otro lado, dando continuidad a las posiciones de García Amado, el paradigma neoconstitucionalista se distingue así:

\begin{abstract}
i) Alejándose de las tesis de la formulación lingüística de las normas jurídicas, el significado de las normas constitucionales no se agota en sus términos y enunciados; lo que abre paso a la interpretación dialógica de la constitución; ii) A pesar de que pueda existir indeterminación semántica en las normas constitucionales, ello no contradice su determinación material; iii) Cerrando el espectro de activismo judicial, al intérprete no le es dado elegir entre varias interpretaciones, solo debe cumplir con los mandatos constitucionalmente dados; iv) El rol del tribunal constitucional es dual, de tipo positivo y negativo. Su función no se agota en la declaratoria de constitucionalidad, sino que inaplica normas jurídicas en casos concretos; v) Parte de poner en duda la racionalidad del modelo del legislador democrático. ${ }^{25}$
\end{abstract}

\title{
Las tesis del constitucionalismo norteamericano
}

El problema del constitucionalismo en Norteamérica se presenta respecto a tres vertientes ideológicas que gozan de un triple alcance: político, moral y jurídico. Por otro lado, supone un avance en la tradición jurídica norteamericana, donde se pasa de interpretar el derecho constitucional como la exegesis del texto propio de la constitución, para analizar el problema tanto de la legitimidad como de su aplicabilidad social y su dimensión política. Las vertientes analizadas son: un constitucionalismo democrático, un constitucionalismo popular y un constitucionalismo aspiracional.

En primer lugar, el constitucionalismo democrático se basa en la idea de un fin colectivo, bajo el cual, por medio de una agencia colectiva, posibilitada por el texto consti- 
tucional, "permite la determinación de una autoridad política." ${ }^{26}$ Esta agencia colectiva, dada por la convivencia tanto del Estado como de los ciudadanos en el marco de un texto constitucional, permite la instauración de, por ejemplo, tratados internacionales, políticas públicas, promulgación de leyes, etcétera. A su vez, presenta diversos actos que, en cierta medida, "abogan por la unidad de agencia que deben perseguir los Estados."27 Es una característica fundamental en los Estados democráticos modernos unificarse en pro de un valor colectivo que tiene su gobierno; así, el calificativo "democrático" obedece a "un principio unificador", ${ }^{28}$ que permite la identificación, aun a pesar del contenido, de la forma institucional estable de una determinada estructura de gobierno.

Este principio unificador se sustenta en dos tesis surgidas a partir del concepto de constitución: por un lado, la constitución implica una pertenencia a un grupo social como "algo que somos", al modo de articulación social y política en comunidad; por otro lado, se habla de un quehacer, como modo de autoconstrucción humana a partir de la integración social. Estos dos aspectos se interrelacionan en cuanto a que es necesario identificar tanto el para dónde va la sociedad como de dónde provino, presentando así un marco problemático justo para la democratización de la interpretación del texto constitucional.

Desde la óptica del constitucionalismo como paradigma jurídico, no es posible deslindar de su esencia la posición de la primacía de la constitución y la garantía de la rigidez constitucional. Stephen Holmes, de la mano de John Elster, plantea la tensión entre constitucionalismo y democracia; en tanto que, si la legalidad de los Estados, por legitimidad, se encuentra sujeta al consentimiento de la mayoría, se cuestiona por qué en un compromiso o acuerdo original i.e. la posición original dificulta ulteriores modificaciones a la estructura y contenido esencial de la constitución. A favor de la fórmula del precompromiso, Holmes cita al juez Robert Jackson, quien al respecto decía: "El propósito mismo de una declaración de derechos fue retirar ciertos temas de las vicisitudes de la controversia política para colocarlos fuera del alcance de las mayorías y los funcionarios, y establecerlos como principios jurídicos que serían aplicados por los Tribunales." ${ }^{29}$

En esa misma línea argumentativa, Holmes encuentra que el constitucionalismo reporta una naturaleza antidemocrática, en tanto que extrae ciertos asuntos de las

\footnotetext{
26. R. Post, "Constitucionalismo democrático y heterogeneidad cultural", en Australian Journal of Legal Philosophy, 25, 2008, p. 185.

27. Ibid., p. 186.

28. Ibid., p. 187.

29. J. Elster, R. Slagtad, Constitucionalismo y democracia, Fondo de Cultura Económica, México D. F., 1999, p. 218.
} 
decisiones o procesos democráticos. Una forma de convalidar la tesis anterior consistirá en comprender la constitución como un freno a la democracia miope, carente de cultura jurídica para algunos y poco educada cualitativamente, que demostrará la necesidad de asumir precompromisos constitucionales ${ }^{30}$ intangibles, ya que: "Los ciudadanos de hoy son miopes; tienen poco dominio de sí mismos; son lamentablemente indisciplinados y siempre tienden a sacrificar principios perdurables en aras de placeres y beneficios inmediatos." 31

Otras formas alternas de abogar por el constitucionalismo se encuentran en la fundamentación de las decisiones ancestrales o una visión del constitucionalismo como un paradigma que impone una serie de limitaciones que, a su vez, promueven la libertad o direccionamiento de un agente libre. Hooker en Holmes arguye la obligatoriedad de las decisiones de los predecesores sobre los presentes, en tanto que, analógicamente, "los vivos y los muertos constituyen un pueblo." Sin embargo, advierte Holmes, son dos los focos que dan lugar a la ruptura o desacuerdo en el compromiso original:

1. Donde un individuo trató de sujetar a otro a través del compromiso original;

2. Donde solo intervinó un sujeto en el contrato. ${ }^{32}$

Ahora, con la figura de la propiedad privada, fue posible la legitimación del precompromiso en el contexto norteamericano, pues, en palabras de Pufendorf "el acto de una generación solo puede obligar a otra cuando algún hombre ha adquirido de él un derecho", y el ejemplo más claro para dicha afirmación ha de ser la propiedad que se hereda en virtud de los acuerdos originales o precompromisos. ${ }^{33}$

Sin embargo, existen posturas contrarias que superponen la democracia al constitucionalismo. Por ejemplo, Martin Shapiro hace dicha superposición, en tanto que cuestiona si el apego al cuerpo de la ley es constitucional y, si además, quieren los ciudadanos que una norma en cuestión sea constitucional, dado que esas normas intocables

\footnotetext{
30. En defensa de la fórmula del precompromiso, José Juan Moreso, a partir de la construcción de un modelo de delimitación del ordenamiento jurídico como una "sucesión de sistemas normativos", cuyo sistema primario u original debe estar compuesto de normas constitucionales, plantea la necesidad del concepto de primacía de la constitución, la cual entra en contradicción con la idea de democracia representativa, pues esta es un mecanismo de decisión basado en el voto de la mayoría, mientras que la idea de primacía constitucional "restringe el conjunto de decisiones que pueden tomarse por la mayoría”. Véase: J. J. Moreso, La indeterminación del derecho y la interpretación de la constitución, Centro de Estudios Políticos y Constitucionales, Madrid, 1997, p. 165; M. Alemany, “Democracia versus constitución (¿precompromiso o paternalismo?)", en Anuario de Filosofía del Derecho, 26, 2010, p. 67.

31. J. Elster, R. Slagtad, Constitucionalismo y democracia, p. 219.

32. Ibid., p. 230.

33. Ibid., p. 234.
} 
ya no reflejan las condiciones actuales de la ciudadanía; así abogan por una naturaleza abstracta e indeterminada en la construcción normativa de los derechos fundamentales, cuya determinación fija ha de corresponder a la dinámica social. ${ }^{34}$ Otras fórmulas de justificación del imperio de la democracia se encuentran en las figuras de la prohibición para obstruir el futuro, desarrolladas por Holmes en los nombres de Hume, Jefferson y Paine, y la dinámica social derivada de la evolución del conocimiento humano. A juicio de Holmes, fue David Hume quien en 1740 encontró una contradicción y, a su vez, la forma inicial de la pugna entre constitucionalismo y democracia, en las bases de la teoría republicana, dado que esta se cimienta en la entidad ficticia del contrato social. Al respecto, Hume cuestionaba si el contrato social no implica una anulación a las generaciones remotas por parte de sus padres, recordando que el Republicanismo aboga por que "una generación fundadora nunca debería condicionar a sus sucesores con un esquema constitucional fijo." ${ }^{35}$ De esta manera, la figura del contrato social aparece como la fórmula del precompromiso en el constitucionalismo.

En este sentido, se presentan dos posturas evidentemente contrarias: la del constitucionalismo que ve a la democracia extrema como "un caballo desbocado" y la democracia que ve al constitucionalismo como un freno a la voluntad mayoritaria. La pregunta subyacente a la presentación de esta tensión es si en términos conceptuales y prácticos es posible la democracia constitucional. A su vez, los predecesores no pueden obligar a sus hijos y, si los hijos repudian las ataduras y promesas impuestas por sus antecesores, entonces, se cuestiona por qué los presentes se preocupan por los del futuro, dado que dicha preocupación significa, de igual forma, un precompromiso. Es de esta forma como aparece la paradoja de la democracia, según la cual, "cada generación desea ser libre para obligar a sus sucesoras sin estar obligadas por sus predecesoras"; ;6 idea que enfrenta el problema del progreso ilimitado. Al mismo tiempo, la paradoja de la democracia se presenta como uno de los dos cuernos del dilema en la respuesta del constitucionalismo del árbol vivo al debate sobre la estructura del paradigma constitucionalista. ${ }^{37}$

\footnotetext{
34. De ahí que, según Waluchow: i) una constitución es un instrumento cuyas disposiciones morales abstractas pueden crecer y adaptarse al cambio sin perder su identidad y función de guía, ii) las disposiciones abstractas de una constitución deben tener permitido crecer y adaptarse a su medio, iii) este proceso puede tener lugar a través de una genuina interpretación constitucional, no a través de la construcción o de una reforma, iv) la autoridad para delimitar las disposiciones morales abstractas es legítima. Véase: W. Waluchow, "Strauss, democracia y constitucionalismo del árbol vivo", en J. Fabra, L. García Jaramillo (eds.), Filosofía del derecho constitucional. Cuestiones fundamentales, Universidad Nacional Autónoma de México, México D. F., 2015, p. 257.

35. J. Elster, R. Slagtad, Constitucionalismo y democracia, p. 221.

36. Ibid., p. 243.

37. Los dos cuernos del dilema son: i) basado en la paradoja de la democracia, una de las limitaciones de la visión abstracta de las disposiciones morales constitucionales es la tesis originalista ya que, según esta, las nuevas generaciones deben atarse a las decisiones de las generaciones precedentes. Waluchow llama este dilema “El problema intergeneracional”, ii) el problema de la discreción: ¿cómo puede ser extendido un concepto moral abstracto de tipo constitucional, atendiendo a criterios
} 
Es importante resaltar que el aspecto constitucional en esta corriente radica en su garantía de legitimación democrática, la cual permite la identificación de compromisos e intereses comunes que subyacen a las exigencias políticas y económicas de un Estado determinado. Sin embargo, en Norteamérica, los compromisos culturales obedecen a un concepto entroncado en la idea de heterogeneidad cultural, en donde se puede: o desarrollar una cultura uniforme o tolerar y promover la diversidad y heterogeneidad cultural. Así, el fin ulterior del constitucionalismo es, en pocas palabras, atender a los reclamos de heterogeneidad cultural, a fin de garantizar mínimos de integridad y legitimidad social.

En segundo lugar, para los populistas el constitucionalismo surge como una reacción a la aparente contradicción entre el ideal democrático y el sistema de autogobierno propuesto por el cuerpo del texto constitucional. Hablar de democracia constitucional implica hablar de dos conceptos diferentes: por un lado, una organización gubernamental y, por otro lado, un Estado constitucional. En este campo, el propósito del constitucionalismo es "arrebatarle cierto poder a las mayorías miopes que -por defecto o ambiciónhan perdido de vista el bien común." ${ }^{38}$ Corresponde, por lo tanto, al juez constitucional velar por el cumplimiento de las restricciones impuestas en la constitución, en donde, como un personaje sumamente calificado por sus condiciones morales, jurídicas y profesionales, está capacitado para emitir un juicio sobre una situación problemática para el derecho. Se presenta así el problema de las elites jurisdiccionales, el cual se justifica en la existencia de una elite que controle la decisión e interpretación de los cánones constitucionales a la luz de una situación jurídica problemática que le dé alcance argumentativo.

Waldron, citado por Post, afirma que el proceso democrático puede ser corregido en la medida en que se entienda que, por medio de las decisiones judiciales, se expresa el sentimiento popular. ${ }^{39}$ Mientras que Kramer, citado también por Post, plantea dos visiones de populismo constitucional, a saber:

1. Jeffersoniana. Esta visión plantea que la participación popular en la decisión judicial implica una defensa a los intereses y a los principios; ${ }^{40}$

2. Madisoniana. Esta visión plantea que la integridad de la interpretación y la salvaguarda de la constitución radica en el texto legislativo de la misma, y su interpretación democrática por parte de las cortes. ${ }^{41}$

\footnotetext{
de imparcialidad y objetividad moral? Los defensores de la tesis del constitucionalismo del árbol vivo consideran como estrategia acudir a las reglas del razonamiento jurídico que brinda el Common Law, en tanto que brindan estabilidad para el sistema jurídico. Véase: W. Waluchow, “Strauss, democracia y constitucionalismo del árbol vivo”, p. 256.

38. D. Peña, “Constitucionalismo popular contestatario”, en Isonomía, 38, 2013, p. 226.

39. Ibid., p. 228. Dado que toda decisión tiránica sacrifica, en cierta medida, los derechos de las minorías.

40. Ibid., p. 229. Es decir, una interpretación popular del alcance de la constitución.

41. Ibid., p. 230. En donde, por medio de deliberación democrática, se vinculan todos los actores de la sociedad.
} 
Así las cosas, el constitucionalismo popular implica una reinterpretación del texto y el alcance de la constitución, tanto a su campo social, es decir, a su finalidad, como a la relación subordinada de los elementos jurídicos y políticos al poder popular. Esto implica, entre líneas, un rechazo a la supremacía judicial, en donde se plantea la crítica a que un tribunal determinado sea la única y final estancia interpretativa.

El populismo, sostiene Kramer, presenta una seria distinción entre actividad jurídica y actividad política, pero en materia de interpretación y alcance de decisiones jurisdiccionales, que afecten bienes y derechos constitucionalmente tutelados, afirma las ventajas de "un proceso interpretativo que vincule los argumentos planteados por una comunidad política en sentido amplio." ${ }^{42}$

En tercer lugar, se plantea un constitucionalismo aspiracional, que aboga por la vinculación de métodos y mecanismos idóneos para la interpretación tanto jurídica como política de los criterios constitucionales, desde perspectivas políticas, sociales, económicas o morales. Los métodos son el de evitabilidad (avoidance) y el anticanon.

El método de la evitación, o mejor llamada evitabilidad, es un canon de interpretación constitucional de sentencias judiciales, que consiste en evitar dificultades prácticas a la hora de enfrentarse a la interpretación de problemas jurídicos a la luz de los preceptos constitucionales; este permite camuflar decisiones judiciales en el marco tanto de doctrina constitucional como de principios históricos y reconstructivos, en busca de principios interpretativos plausibles. ${ }^{43}$

Es un principio cardinal de la interpretación judicial del derecho en la medida en que permite la reconstrucción de criterios judiciales que superen brechas políticas, como un mecanismo de vinculación de decisiones políticas y jurídicas a la luz de la actividad judicial. La evitabilidad de casos constitucionalmente relevantes implica la innovación en las alternativas de decisión de casos difíciles, por medio de criterios interpretativos judiciales que sustituyan la modificación legal del ordenamiento en pro de dicha solución jurídica.

Por otro lado, se entiende el anticanon como la negación de la utilización de un canon de interpretación en un caso concreto, por cuanto la decisión, tanto en su proceso de interpretación como en su cuerpo justificatorio, presenta errores que permiten no la solución de la circunstancia sometida a estudio, sino una decisión completamente salida de ellos.

42. Ibid., p. 231.

43. Este fenómeno tiene visos políticos, en la medida en que garantiza reescribir la historia de la constitución, en donde un activismo, a la hora de la función judicial, permite usar el canon como un criterio de cambio legal. Véase: N. Katyal, T. Schmidt, "Active Avoidance: The Modern Supreme Court and Legal Change”, en Harvard Law Review, 128, 2015, p. 2112. 
La interpretación anticanónica es producto de la función judicial norteamericana, en donde los criterios de decisión pueden incluir tanto los clásicos cánones de interpretación en derecho como criterios auxiliares, como morales, políticos o económicos, que amplían el espectro de la decisión a marcos justificatorios más amplios de los que se pueden llegar a controlar por parte del juzgador. El anticanon es la expresión fáctica del peligro que se da al emplear la reconstrucción de decisiones judiciales, por cuanto, al admitir criterios morales en tal actividad, propondría una suerte de liberalidad a la hora de entender cómo resolver en derecho un problema jurídico. ${ }^{44}$

Concluyendo, son varios los puntos de intersección entre la tradición norteamericana y la tradición continental en materia de ismos constitucionales. Primero, el eje rector de las tradiciones constitucionalistas sigue siendo ubicado en el papel de la democracia, en el marco de los Estados constitucionales de derecho; situación que, de fondo, puede recoger las versiones del constitucionalismo así: por un lado, algunas de las versiones constitucionalistas apuestan a un margen de rigidez constitucional; situación que traslapada puede ser ubicada en las situaciones del anticanon constitucional norteamericano y la interpretación por vía originalista. Por otro lado, visiones como las del neoconstitucionalismo, el constitucionalismo del árbol vivo, el constitucionalismo aspiracional y el constitucionalismo democrático apuestan a una construcción no rígida de los derechos fundamentales, al entender que su desarrollo corresponde a la dinámica social; situación para la cual los originalismos habrían de constituir un limitante en la construcción de la categoría fundamental. Segundo, por el lado de la tradición continental, el debate entre constitucionalismo y neoconstitucionalismo viene dado, entre otros casos, por la hipótesis de la superación del paradigma positivista; sin embargo, ambas tendencias no son ajenas a los postulados del positivismo jurídico incluyente. En cambio, en el espacio de los constitucionalismos norteamericanos, el punto de discusión, por corresponder a una herencia realista, no viene dado en la superación del positivismo jurídico, sino en la posibilidad de un derecho constitucional legítimo, que, por supuesto, se interpenetra con los sistemas de la política y la moral.

44. Véase: J. Green, “The Anticanon”, en Harvard Law Review, 125, 2011, p. 404. 